It is well known that Franklin's preserved meats and vegetables were supplied by Goldner, were painted red, and stamped "Goldner Patent". There is no record of official Franklin supplies having come from Gamble, but tins of this nature may have formed part of the officers' private stores. There is the same difficulty about the official Belcher stores, as Belcher himself states that his preserved meat, soups and vegetables were supplied by Hogarth. Kellett's command may, however, have had different supplies, and there is also the possibility of these being officers' private stores.

\title{
RECENT INTERNATIONAL WHALING CONFERENCES AND THE RESUMPTION OF WHALING SINCE THE WAR
}

Although the whaling industry was not entirely suspended throughout the war, the Antarctic season of 1945-46 was the first in which pelagic whaling was resumed on any considerable scale. A new era in whaling has begun, and this note is intended to be a short review of the present position. For this purpose it is necessary to recall that before the war the pelagic catches in the Antarctic had risen to a dangerously high level. In 1937-38 the total Antarctic catch reached 46,039 whales with 31 factory ships, but in 1938-39, in spite of an increased whaling fleet, it fell to 38,356 with 34 factory ships. Investigations, based on statistics of the catches and biological examination of the whales, showed that the stocks of Blue and Humpback whales had already been substantially affected, and although the stock of Fin whales appeared to be in a stronger condition it could not be supposed that they would long support an industry on the pre-war scale.

After the outbreak of war a slightly reduced whaling fleet operated in 1939-40, and a considerably smaller number in 1940-41. Pelagic whaling was then suspended, but whaling on a small scale was continued at certain shore stations, including one at South Georgia.

It will be recalled that the regulation of whaling is based on the International Agreement of 1937. The principal articles of this Agreement, and the Protocol of 1938, prescribed limitation of the Antarctic season to three months (8 December to 7 March), minimum lengths for each species, avoidance of waste in the treatment of carcasses, temporary protection of Humpbacks, a temporary sanctuary in the Pacific sector of the Antarctic, and certain other limits to the areas available for whaling. The Agreement firmly established the principle of international control, and the stock of whales would no doubt have been more severely affected if the regulations had not been in force. There is little doubt however that in the long run they would be inadequate for the permanent maintenance of the stock. The virtual suspension of whaling during the war provided an opportunity to consider whether the provisions of the Agreement could in any way be improved, but the situation was complicated by the world shortage of oils and fats, and the urgent need for a maximum production of whale oil as soon as whaling could be resumed. 
The first International Conference on post-war whaling was held in London in January 1944.1 An account of this has already appeared in The Polar Record, July 1944, p. 193. The main problem was to reconcile the short-term need for oil, and the long-term need to preserve the stocks of whales. It was decided that the first post-war Antarctic season should be extended to four months so as to increase the production of oil, that the protection of Humpbacks should be maintained, and that "During the first season, the number of baleen whale caught... shall not exceed 16,000 Blue whale units". (A Blue whale unit equals 1 Blue, 2 Fin, $2 \frac{1}{2}$ Humpback or 6 Sei whales.) It was clear that 16,000 units was a figure which could not possibly be reached in the first season, for many of the whaling ships had been lost during the war, but this clause was of vital importance since it introduced the new principle of an overall limit to the Antarctic catches. It may be argued that the only effective method of avoiding excessive hunting is to restrict the total number of whales caught. Such limitation had been considered at pre-war conferences, but had not then been found practicable. Its introduction now, however, would indicate a provisional ceiling to which the new Antarctic industry could be built up.

A second conference took place in London in November 1945, Mr A. T. A. Dobson presiding. ${ }^{2}$ The following governments were represented: South Africa, Australia, Canada, Denmark, France, Mexico, Netherlands, Newfoundland, New Zealand, Norway, United Kingdom, and United States. The object of the conference was to consider what special measures should be put into force in respect of the season 1946-47. The demand for oil and the protection of the stock had, as before, to be taken into consideration, and it was also regarded as important "that any temporary relaxation of the existing regulations should not serve to encourage countries that had not taken part in whaling operations before to enter the industry only to find that ultimately their expeditions might not prove financially profitable". It was agreed that the open season should again be for four months, but that the period should be from 8 December to 7 April, and that the protection of Humpbacks and the limit of 16,000 Blue whale units should continue. It was arranged that the International Bureau. for Whaling Statistics should receive weekly reports of the catches of each factory ship, and if necessary calculate a date for the termination of whaling if it should appear that the annual quota might be reached before the end of the season. The Final Act recommends that the various governments should take all practicable steps to prohibit the delivery of whaling vessels or equipment to any nation not a party or signatory to the Whaling Agreement of 1937. Collaboration in research on whales is also recommended. It is expected that a further conference will take place shortly in Washington.

Pelagic whaling was resumed in 1945-46 with nine factory ships (three British and six Norwegian), and it was clearly of considerable importance to

1 Protocol on the International Regulation of Whaling, with Final Act of the Conference, 7 February 1944. London: H.M. Stationery Office, Cmd. 6510, 1944.

- Protocol amending the International Agreement of 8th June 1937, and the Protocol of 24th June 1948 for the Regulation of Whaling, with the Final Act of the Conference, 26 th November 1945. London: H.M. Stationery Office, Cmd. 6725, 1946. 
assess any change which had taken place in the condition of the stock of whales as a result of the reduction of whaling in wartime. It was hoped that the number of whales would have increased, though it is hardly safe to count on any substantial recovery in a depleted population of mammals whose reproductive capacity cannot be compared with that of, for example, the populations of fish. Full details of the catches have not yet been published, but they appear to have been on the whole disappointing, and so far as can be seen at present there is no evidence of a substantial improvement of the stock. It must be remembered, however, that the rather poor catches may be due simply to exceptional weather and oceanographical conditions. It would be premature to express any opinion on the condition of the stock until the statistics of catches have been analysed, and the data obtained by biologists working in the factories have been examined. It may indeed be necessary to compare the results of several successive seasons before any reliable comparison can be made of the condition of the stock before and after the war.

N. A. MACKINTOSH 